\title{
Promoting Diversity and Inclusion through Engagement: The APSA 2018 Hackathon
}

Mala Htun, University of New Mexico

ABSTRACT Organizations-from academic and professional associations to private corporations and police forces-face challenges promoting diversity and inclusion among their workers and affiliates. Instead of training and regulations, recent research recommends mechanisms that engage managers and leaders in activities that involve behavioral changes. This article describes how we put the managerial engagement approach into practice by organizing a "Diversity and Inclusion Hackathon" at the 2018 annual meeting of the American Political Science Association. With 11 teams focused on a range of topics, the hackathon attracted more than 200 people and produced multiple outputs. It engaged scholars from a range of backgrounds, social identities, institutions, ranks, and beliefs in the generation of new norms, programmatic ideas, and plans for the profession. Although we cannot infer causality, analysis of the APSA Annual Meeting evaluation survey reveals that hackathon participants are significantly more likely to express positive perceptions of the conference.

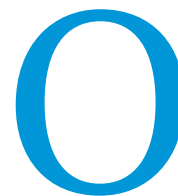

rganizations-from academic and professional associations to private corporations and police forces-want to improve diversity and create more inclusive climates. Although we know a great deal about the value of diversity and inclusion, we know less about how to achieve it. Recent research by Dobbin and Kalev (Dobbin and Kalev 2016; Dobbin, Schrage, and Kalev 2015) finds that many common strategies to promote diversity are ineffective or even counterproductive. Instead of the usual practices of diversity promotion, they recommend that organizations create mechanisms to engage managers and leaders as active allies in efforts to reduce discrimination and foster inclusion.

This article describes how Alvin B. Tillery Jr., Kathleen Thelen and I put the managerial engagement approach into practice in an academic context by organizing a "Diversity and Inclusion Hackathon" at the 2018 annual meeting of the American Political Science Association (APSA). The hackathon engaged more than 200 people and produced multiple outputs, including a website with resources for graduate students; guidelines for model male behavior; and minimum standards for the treatment of contingent faculty; among others. The event received rave reviews: a few prominent scholars told us that the hackathon generated more

Mala Htun id is professor of political science at the University of New Mexico. She can be reached at malahtun@unm.edu. energy than they had seen in decades at an APSA meeting. After identifying the sociological processes at work, we present an analysis of survey data showing that hackathon participants are more likely than nonparticipants to express positive perceptions of the annual meeting. The article concludes by speculating about the research that is needed to generalize the hackathon as a mechanism for change in a broader range of organizations.

\section{PROMOTING DIVERSITY AND INCLUSION IN PRACTICE}

In a series of influential studies, Dobbin and Kalev (Dobbin and Kalev 2016; Dobbin, Schrage, and Kalev 2015; Kalev and Dobbin n.d.) show how and why diversity programs frequently fail. Mechanisms to control bias, such as performance evaluations and hiring tests, trigger resentment of external controls and are usually circumvented. Diversity training, especially when mandatory and legalistic, incites resistance and backlash. People do not like being told what to do and they defy reeducation programs that "blame and shame" them. Grievance procedures-intended to make harassment, discrimination, and incivility easier to report-are underutilized because they expose the person being targeted to retaliation and generate data that allow managers to understate the extent of the problem (Ayres, Chwe, and Ladd 2017; Porter 2018).

Other work in sociology provides additional grounds for pessimism about diversity-promotion efforts. According to Edelman's (2016) study of hundreds of cases, US courts tend to find that 
the mere existence of an organizational nondiscrimination policy, training, or grievance procedure constitutes evidence of "reasonable care" to prevent harassment and hostile working environments. Regardless of their efficacy, and despite evidence of enduring wage gaps or misconduct, simply having such programs in place tends to absolve employers of liability for discrimination and to requirements that women and minorities participate on search committees, task forces, and other decision-making groups may contribute to excessive service loads and impede their progress toward tenure and promotion.

Training and regulations may produce good results in some contexts, particularly when prior work cultivates a positive orientation

\section{The hackathon engaged more than 200 people and produced multiple outputs, including a website with resources for graduate students; guidelines for model male behavior; and minimum standards for the treatment of contingent faculty; among others.}

shield them from punitive damages (Bisom-Rapp 2018; Edelman 2016; Gertner 2018). The judiciary thus supplies incentives for diversity programs to serve merely as "symbolic structures."

These findings resonate with other conclusions of social science research. When new regulations do not align with prominent social norms and entrenched behaviors, people tend to evade them and state officials may consciously opt not to enforce rules (Amengual 2016; Holland 2016). Some public-health interventions and efforts to "correct" misperceptions may produce boomerang effects. To reassert control against messages perceived as patronizing-such as campaigns against smoking, drinking, and sexual assault-some people double down on the proscribed behavior (Byrne and Hart 2009; Malamuth, Huppin, and Linz 2018). Public-education campaigns to disseminate scientific facts and change opinions about climate change, Barack Obama's birthplace, and gun laws may induce people to hold more tightly to their views, especially if they are motivated by partisanship (Flynn, Nyhan, and Reifler 2017; Kahan et al. 2012). By heightening the salience of gender and sexuality in social contexts, sexual-misconduct training can activate traditional gender stereotypes (Tinkler 2012; 2013), while affirmative consent standards, which classify much ambiguous behavior as assault, may reduce women's willingness to report their experiences (Htun et al. 2018).

How can and should organizations promote diversity and inclusion? The Dobbin-Kalev research shows that successful corporate strategies share a common feature: they engage leaders and managers in proactive efforts to improve organizational climates. Creating diversity committees and task forces to collectively study problems and propose solutions holds people accountable and involves them in the search for solutions rather than merely penalizing biased behavior. In addition, programs that encourage people of different backgrounds and identities to work together, such as mentoring and cross-disciplinary teams, help to break down biases (Dobbin and Kalev 2016; Dobbin, Schrage, and Kalev 2015).

Academic organizations-including universities and professional associations-should take these corporate lessons seriously. Yet much contemporary discussion, including in political science, still centers on ineffective practices. Implicit bias training, for example, seems appealing because we want to believe that people will change their behavior in response to evidence. However, training is likely to be ignored by or trigger hostility from the people who need it most. Regulations to control bias, such as a ban on "manels," may overburden the people they are intended to help-for example, by saddling women with token appearances as discussants or chairs at professional meetings. Well-intentioned toward diversity promotion. For example, the WISELI program at the University of Wisconsin created buy-in among faculty for their "breaking the bias" workshops, which subsequently triggered changes in departmental climates and resulted in women feeling more valued (Carnes et al. 2015; Fine et al. 2014; Stewart and Valian 2018).

Research and recommendations from the private sector presume a different implementation infrastructure than exists in universities and scholarly professions. Academic leaders are more constrained than CEOs and their "subordinates" may shirk responsibilities with few consequences. These differences in organizational type imply that strategies for diversity and inclusion in the academy must rely more on voluntary participation and bottom-up compliance. As we explain, the hackathon represents one effort to apply corporate best practices in an academic context.

\section{THE CONCEPT AND ORIGINS OF THE HACKATHON}

Originally, hackathons were events where computer programmers came together to write code or build an app. Recently, popular understandings of the concept have expanded to include intensive, collaborative work on a problem or question. For example, in 2017, Srivastava and Lewis (2017) organized a hackathon on increasing diversity and inclusion at the annual meeting of the Society for the Improvement of Psychological Science. In April 2018, the MIT Media Lab collaborated in the production of a breastfeeding-innovation hackathon (its second). Participants included parents, policy makers, engineers, activists, health care professionals, babies, and toddlers. ${ }^{1}$ We also learned from other creative hackathons and the people who organized them, including Rosenweig's (2017) "We the People/Hack for Democracy" at the MIT Gov/Lab.

We conceived of the APSA Hackathon as an event to launch the implementation phase of Kathleen Thelen's Presidential Task Force on Women's Advancement. We wanted the task force studies on women's career trajectories in the discipline, experiences of professional service, gender publication gaps, and effects of mentoring on advancement to generate actionable recommendations, and we wanted to crowdsource other ideas.

Participation in the hackathon was voluntary and we were able to reduce costs by holding the event during the APSA Annual Meeting. Thanks to a National Science Foundation (NSF) grant secured by APSA on behalf of the Task Force, we provided hackathon scholarships for more than 20 people through the Travel Grant program. ${ }^{2}$ 
We began to plan the event in December 2017 and January 2018. We reached out to colleagues working on promising ideas and seeded 10 organized teams before the June 30 deadline. Through the APSA website, each team described its plans to recruit additional members. An 11th team walked on at the event. We designed a logo and printed it on T-shirts for participants, and many wore them during the event.
Second, the hackathon brought people from different networks, ranks, institutions, backgrounds, and fields of study into collaborative relationships. Conference panels, by contrast, typically are designed to include people from the same networks working on similar topics. At the APSA hackathon, the chair of the Yale political science department participated in the contingent faculty team; $\mathrm{PhD}$ candidates worked with senior scholars Jenna

\section{We conceived of the APSA Hackathon as an event to launch the implementation phase of Kathleen Thelen's Presidential Task Force on Women's Advancement. We wanted the task force studies ... to generate actionable recommendations, and we wanted to crowdsource otherideas.}

\section{THE PROCESS}

Some 200 to 250 people participated in the hackathon, which is more than double the average APSA plenary-session attendance and 10 times greater than an average panel session. ${ }^{3}$ To begin, team leaders gave 1-minute pitches to recruit additional participants. We served a pizza lunch and then candy and snacks approximately halfway through the event. Throughout the day, "roving mentors"-people chosen for their experience in relevant issue areas such as Title IX compliance and ombudsman trainingcirculated among the teams, offering helpful information and advice. In the final hour of the event, judges interviewed each team, probing what they had learned and created. The judges presented awards during a closing ceremony, and the event ended with a reception featuring an open bar and music playlist built specifically for the event by a professional DJ.4

There was tremendous energy in the room all day, evinced by social media traffic and photographs. Figure 1 depicts a word cloud with users, words, and hashtags tweeted during and around the hackathon. The most prominent terms are shown in larger font and occupy a more central location. Unusual for a diversity event, many tweets emphasized the word "men," reflecting the hackathon's efforts to engage men in conversations about gender equality. Supplementary materials $\mathrm{C}$ provide additional analysis of the volume and sentiment of twitter conversations. ${ }^{5}$

The hackathon operated under laissez-faire principles, with each group responsible for its own schedule, process, and product. The overall structure, however, appeared to nurture several processes that research has identified as important components of social change. First was the generation of legitimate social norms. Hackathon teams engaged in collective authorship of new norms, including behavioral guidelines, teaching protocols, and minimum employment standards.

For example, in Macartan Humphreys and Jessica Preece's team on "How Can Men Promote Gender Equality?," prominent men in the profession facilitated a series of breakout sessions on building inclusive networks, recognizing achievements, reducing biases in hiring and promotion, and diversifying syllabi, among others. The team leaders' decision to give men responsibility was not uncontroversial, but it got men in the door. As Preece explained, "We wanted to create a place where men can discuss and reflect with each other.... Men talking to men about this is likely to be a more effective norm-producing strategy than women talking to men." ${ }^{6}$
Bednar and Michael Chwe; women from multiple ranks-from a former university president to graduate students-participated in the men and gender equality team; and so on. These diverse collaborations generated fresh interactions and understandings, forged new connections and relationships, and may have built trust among different groups.

Third, the hackathon has the potential to create "common knowledge" about diversity and inclusion. As Chwe (2013) points out, people often fail to adhere to a new norm, even if they want to, because they lack information about the probable behavior of others. However, if people know that others are aware of new norms and are likely to comply, they are more inclined to modify their own behavior (Chwe 2013). At the hackathon, participants observed many others-including scholars they admire and others less familiar-working together to develop behavioral guidelines, best practices, and recommendations. Tweets, Facebook updates, and PSNow posts broadcast stories from the hackathon to the broader community.

In these ways, the hackathon engendered a potentially transformative experience for participants. The room pulsed with excitement, which drew people in and made them feel part of something big and important. As Basak Taraktas, currently assistant professor at Bosphorus University in Istanbul, remarked: "The Hackathon broke down the hierarchy of presenter-commentator-audience... [and] allowed us to channel the energies of multiple people on one shared project, which helped to create a 'we' feeling."7

\section{ANNUAL MEETING CLIMATE}

Analysis of the APSA Annual Meeting evaluation survey reveals that participation in the hackathon is associated with positive perceptions and overall satisfaction with the conference. However, as discussed herein, we cannot infer causality with these data. 1,707 people answered the survey, of whom 128 said they participated in the hackathon, for a response rate of $25.4 \%{ }^{8}$

Figure 2 depicts results of a multivariate OLS regression on perceptions of the annual meeting. The left panel shows the relationship between participating in the hackathon and respondents' assessment of the annual meeting's climate, with statistically significant coefficients presented in black. ${ }^{9}$ The figure shows that people who participated in the hackathon are significantly more likely to view the APSA Annual Meeting as welcoming and inviting, even as women overall are significantly less likely to affirm a welcoming climate. ${ }^{10}$ 
The right panel of figure 2 shows the relationship between participating in the hackathon and respondents' satisfaction with the annual meeting. The results show that people who participated in the hackathon are significantly more likely to agree that the annual meeting "met or exceeded" their expectations. ${ }^{11}$

In supplementary materials $\mathrm{B}$, additional analyses show differences in mean responses between hackathon participants and other annual meeting attendees, disaggregated by gender identity and racial and ethnic identity.

Analysis of the survey data does not demonstrate that the hackathon altered attitudes. It is plausible that people already inclined to perceive a welcoming climate or to be satisfied with the annual meeting were more likely to participate in the hackathon. Combined with our own observations, social media conversations, and testimony from people who were present, however,

\section{At the hackathon, participants observed many others-including scholars they admire and} others less familiar-working together to develop behavioral guidelines, best practices, and recommendations. Tweets, Facebook updates, and PSNow posts broadcast stories from the hackathon to the broader community.

Figure 1

\section{Word Cloud of Twitter Traffic about the APSA Hackathon}

Word Cloud

APSA Hackathon

Date range: Aug 22nd, 2018 to Sep 30th, 2018

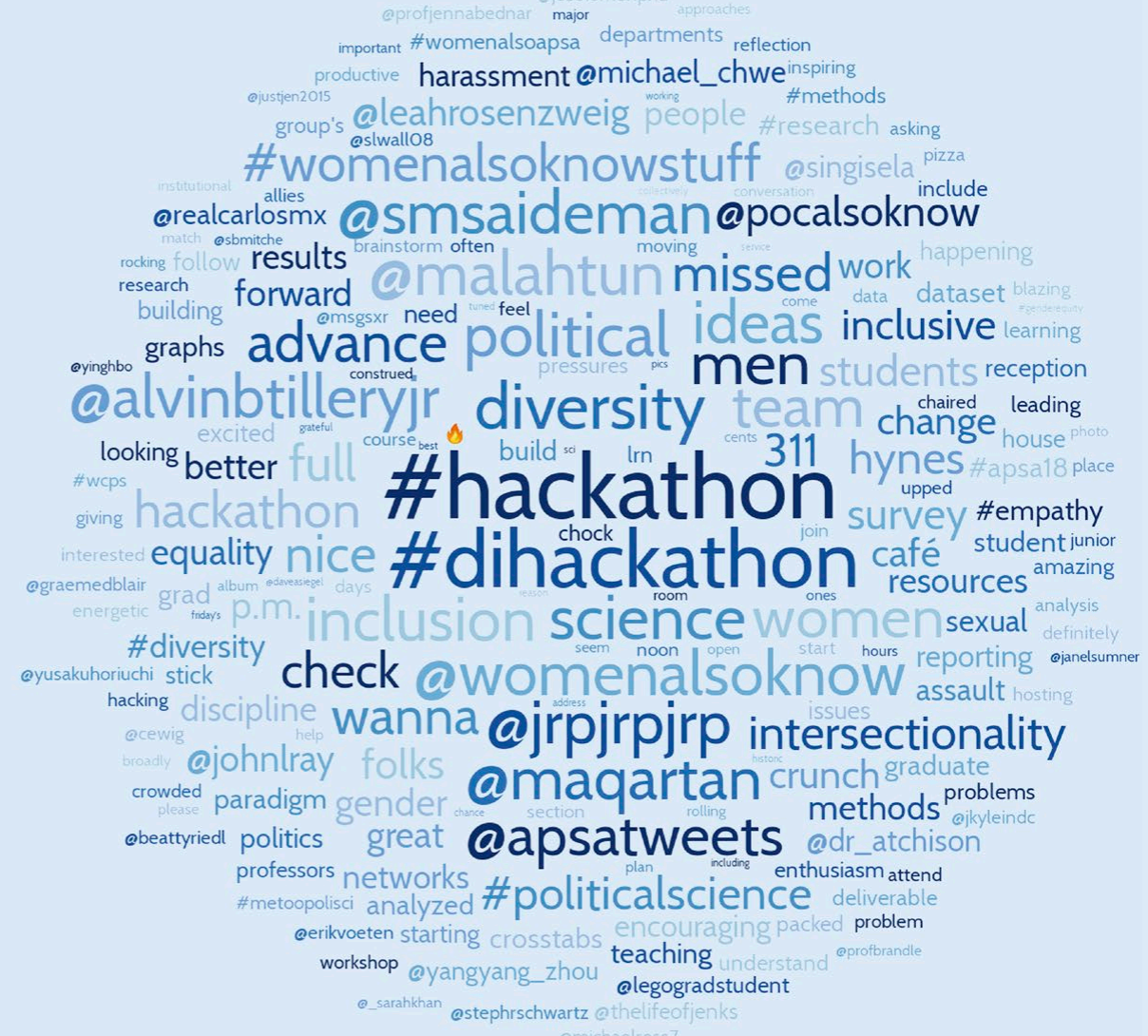




\section{Figure 2 \\ OLS Regression on Annual Meeting Evaluation}

\author{
The APSA meeting \\ has a welcoming and \\ inviting climate \\ (baseline: 3.77 )
}

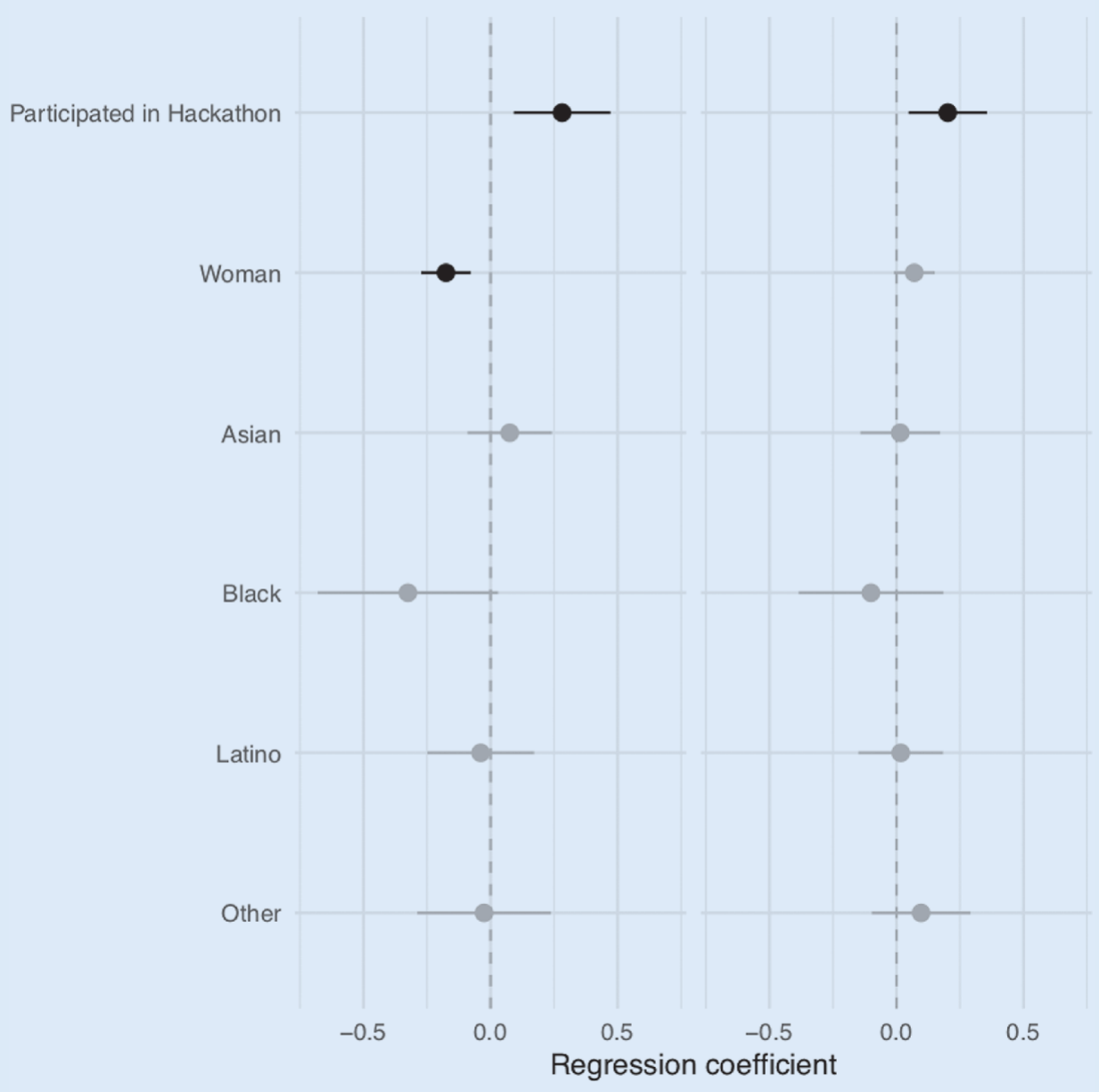

Note: Strongly disagree (1), Disagree (2), Neither (3), Agree (4), Strongly agree (5)
The APSA meeting
has met or exceeded my expectations

(baseline: 3.90)

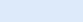

- a set of model behavioral guidelines for men who want to promote gender equality

- a new website for graduate students that contains results of a climate survey, tips for departments to improve graduate student quality of life, and resources for collaboration on Github

- minimum standards for the treatment of contingent faculty and action items for stakeholders

- data visualization of the status of diversity and inclusion in different contexts and results of new initiatives

- findings and recommendations on the connections among gender, notability, and status in the political science discipline

- plans to improve recruiting and training and to develop partnerships for the Society of Political Methodology's AERoPUP program

- guidelines to teach intersectionality in political science, including activities, readings, questions to ask, and ways to obtain university buy-in

- best practices and resources to teach about race and genomics

- recommended actions for publishers, journal editors, peer reviewers, authors, and external evaluators to reduce gender citation bias

we believe the survey data provide additional grounds to infer that the hackathon produced a positive effect on participants. For example, we received unsolicited, enthusiastic comments from senior members of the profession who observed the event. Margaret Levi told us, and then tweeted, that "[i]n my 40 years of coming to APSA, I've NEVER seen such energy AND good content." Skip Lupia wrote, "I've been attending APSA meetings for 30 years. That was the most exciting room I've ever been in."12

\section{PRODUCTS}

The hackathon generated multiple products, all of which are described on the event's website. ${ }^{13}$ They include the following:

- recommendations about ways APSA can improve the disciplinary climate, including a certification system to incentivize and make visible institutional efforts to create a positive climate, and a discipline-wide incident-reporting system
- five concrete suggestions to recruit and retain a diverse faculty, including diversity catalysts, search-committee training, and attention to diversity and inclusion work during faculty annual reviews

In the six months following the hackathon, we received reports that some participants are implementing the ideas generated there. For example, the contingent faculty team published a set of articles in PS: Political Science \& Politics to announce the minimum standards it developed at the hackathon (Orr and Czastkiewicz 2019). The team hopes that the APSA Council eventually will endorse these standards. APSA recently announced the launch of a reporting platform for harassment and discrimination that occurs during the annual meeting and at other APSA-sponsored events-an initiative advocated by the Women's Caucus, APSA staff, and members of the APSA Council, and encouraged at the hackathon. ${ }^{14}$ Based on plans that emerged at the hackathon, the Society for Political Methodology requested NSF funding for 
summer methods training for a small cohort of undergraduate students from underrepresented minority groups. The graduatestudent team plans to conduct another survey and to collaborate on a paper reporting the results. Finally, as news of the event spread, diverse groups from the academy to the corporate sector contacted us asking for advice on how organize their own hackathon.

\section{CONCLUSION}

We conceived of the APSA hackathon as a novel way to address problems of harassment, implicit and institutionalized biases, exclusive networks, and unwelcome climates that contribute to unequal conditions and leaky pipelines for women and minorities in political science. Since these problems are social and political, not only technical and intellectual, they are particularly suited to the hackathon method. Like other contexts in which people share views and deliberate, such as a policy committee or a task force, the hackathon built understanding. However, it also involved "hacking"-that is, collaborative, focused work toward a concrete outcome within a fixed period. The requirement to produce something new gave participants a collective purpose and bonded their efforts. The hackathon thus joined the consensus-building logic of an inclusive parliamentary deliberation to the collective identitybuilding dynamics of playing on a sports team or working on a political campaign.

To refine the hackathon method and to generalize it to other problems and contexts, we must do more research to identify with greater precision whether and how a hackathon catalyzes social change. Which components matter most? What was unique about our event, and which aspects can be scaled? Did "selection bias" in our recruitment methods generate an inflated perception of the hackathon's success? We need to gather data on participant orientations-their trust, enthusiasm, and knowledge-before and after the event, or possibly randomize inclusion in the hackathon "treatment" and compare the views and experiences of participants with a control group. We then could assess whether the hackathon produced heterogeneous effects on participants, such as excitement in some but hostility toward diversity promotion in others. We also need to explore how team-level variation-in preparation, degree of structure, and group dynamics-shaped differences in satisfaction and output quality.

Even without a formal evaluation of the 2018 APSA hackathon, we have enough evidence from various sources to suggest that the event produced a positive impact on participants and that its energy spread more broadly. Testimonies, social media conversations, and team products demonstrate that the hackathon engaged scores of people in creative work and generated fruitful collaborations on multiple topics. Participants built new relationships, acquired skills, and learned from others with different perspectives. What is more, it was fun!

\section{SUPPLEMENTARY MATERIAL}

To view supplementary material for this article, please visit https://doi.org/10.1017/S1049096519000593

\section{ACKNOWLEDGMENTS}

The hackathon was co-chaired by Mala Htun and Alvin B. Tillery, Jr., with the collaboration of APSA President Kathleen Thelen. Htun wrote the paper and Thelen and Tillery reviewed drafts and made suggestions. The three of us are grateful to Betsy Super, Kim Mealy, Megan Davis and APSA staff for their support and work on the project. Above all, we thank the amazing team leaders, judges, roving mentors, volunteers, and participants who all contributed to the success of the event. Brian Humes and the National Science Foundation (Eager Award No. 1748777) helped make the hackathon possible. Michael Chwe, Cassy Dorff, Yusaku Horiuchi, Francesca Jensenius, Melanie Moses, Leah Rosenweig, Betsy Super and anonymous reviewers gave helpful comments on this paper, Melanie Sayuri Dominguez provided research assistance, and Gary King supplied crucial advice and analysis of social media. This material is based in part on work supported by the National Science Foundation ADVANCE program under Grant No. 1628471. -

\section{NOTES}

1. See "Make the Breast Pump Not Suck Hackathon." Available at www. makethebreastpumpnotsuck.com.

2. To facilitate their participation, APSA waived the conference registration fee for key members of the graduate student team.

3. In 2017 and 2018, the average attendance at an APSA panel was 18-19 people; at a plenary and keynote session, it was around 90 people. Personal communication with Betsy Super, October 11, 2018. As we did not take attendance at the hackathon, 200 to 250 represents our best guess.

4. Judges included Danielle Duplin, Rodney Hero, David Lake, Skip Lupia, Melissa Nobles, Shayla Nunnally, and Frances Rosenbluth.

5. We are grateful to Gary King and Crimson Hexagon for these analyses.

6. Email communication from Jessica Preece, August 22, 2018.

7. Personal communication, December 30, 2018.

8. Supplementary materials A contains a more detailed description of the survey.

9. The dependent variable is treated as a continuous variable with numerical values attached to the following answers: Strongly Disagree (1), Disagree (2), Neither (3), Agree (4), Strongly Agree (5). Survey respondents who selected certain options (e.g., "prefer not to disclose") were excluded from the analysis. See supplementary materials A.

10. The baseline values for this model are "Not Participated," "Man," and "White." Holding all else constant, hackathon participation is associated with an increase in the dependent variable from 3.77 to 4.05 , an increase of $7.4 \%$.

11. The baseline values are the same as in the previous model. Hackathon participation is associated with an increase in the value of the dependent variable from 3.90 to 4.10, an increase of $5.1 \%$.

12. These two testimonies and others are available on the hackathon website: https://connect.apsanet.org/hackathon.

13. Available at https://connect.apsanet.org/hackathon/products.

14. For information about the APSA Ethics Point incident reporting online platform and to get access to the platform, see: https://www.apsanet.org/ divresources/sexualharassment. You can reach the platform directly at this link: https://secure.ethicspoint.com/domain/media/en/gui/580o8/index.html.

\section{REFERENCES}

Amengual, Matthew. 2016. Politicized Enforcement in Argentina: Labor and Environmental Regulation. New York: Cambridge University Press.

Ayres, Ian, Michael Chwe, and Jessica Ladd. 2017. "Act-Sampling Bias and the Shrouding of Repeat Offending." Virginia Law Review Online 103: 94-102.

Bisom-Rapp, Susan. 2018. "Sex Harassment Training Must Change: The Case for Legal Incentives for Transformative Education and Prevention." Stanford Law Review Online 71: 62-75.

Byrne, Sahara, and Philip Solomon Hart. 2009. “The Boomerang Effect: A Synthesis of Findings and a Preliminary Theoretical Framework." Annals of the International Communication Association 33 (1): 3-37.

Carnes, Molly, G. Devine Patricia, Linda Baier Manwell, Angela Byars-Winston, Eve Fine, E. Ford Cecilia, Patrick Forscher, Carol Isaac, Anna Kaatz, Wairimu Magua, Mari Palta, and Jennifer Sheridan. 2015. "Effect of an Intervention to Break the Gender Bias Habit for Faculty at One Institution: A Cluster Randomized, Controlled Trial." Academic Medicine: Journal of the Association of American Medical Colleges 9o (2): 221-30.

Chwe, Michael Suk-Young. 2013. Rational Ritual: Culture, Coordination, and Common Knowledge. Princeton, NJ: Princeton University Press.

Dobbin, Frank, and Alexandra Kalev. 2016. "Why Diversity Programs Fail." Harvard Business Review 94 (7-8): 52-60. 
Dobbin, Frank, Daniel Schrage, and Alexandra Kalev. 2015. "Rage Against the Iron Cage: The Varied Effects of Bureaucratic Personnel Reforms on Diversity." American Sociological Review 8o (5): 1014-44.

Edelman, Lauren B. 2016. Working Law: Courts, Corporations, and Symbolic Civil Rights. Chicago: University of Chicago Press.

Fine, Eve, Jennifer Sheridan, Molly Carnes, Jo Handelsman, Christine Pribbenow, Julia Savoy, and Amy Wendt. 2014. "Minimizing the Influence of Gender Bias on the Faculty Search Process." In Gender Transformation in the Academy, ed. Vasilikie Demos, Catherine White Berheide, and Marcia Texler Segal, 267-89. Bingley, England: Emerald Group Publishing Limited.

Flynn, D. J., Brendan Nyhan, and Jason Reifler. 2017. "The Nature and Origins of Misperceptions: Understanding False and Unsupported Beliefs about Politics." Political Psychology 38: 127-50.

Gertner, Nancy. 2018. "Sexual Harassment and the Bench." Stanford Law Review Online 71: 88-98.

Holland, Alisha C. 2016. "Forbearance." American Political Science Review 110 (2): 232-46

Htun, Mala, Carlos Contreras, Melanie S. Dominguez, Francesca R. Jensenius, and Justine Tinkler. 2018. "Effects of Mandatory Sexual Misconduct Training on University Campuses." Paper presented at American Political Science Association Annual Meeting, Boston.

Kahan, Dan, Ellen Peters, Maggie Wittlin, Paul Slovic Lisa Larrimore Ouellette, Donald Braman, and Gregory Mandel. 2012. "The Polarizing Impact of Science Literacy and Numeracy on Perceived Climate Change Risks." Nature Climate Change 2 (10): $732-35$.
Kalev, Alexandra, and Frank Dobbin. N. d. "Try and Make Me! Why Corporate Diversity Training Fails." Unpublished paper.

Lewis, Neil, Jr. 2017. "Reflections on SIPS.” The Hardest Science. Blog by Sanjay Srivastava. Available at https://thehardestscience.com/2017/o8/11/reflectionson-sips-guest-post-by-neil-lewis-jr.

Malamuth, Neil, Mark Huppin, and Daniel Linz. 2018. "Sexual Assault Interventions May Be Doing More Harm Than Good with High-Risk Males.” Aggression and Violent Behavior 41 (July-August): 20-24.

Orr, Susan, and Veronica M. Czastkiewicz. 2019. "Considering Contingency: A Call to Action.” PS: Political Science \& Politics 52 (3): doi:10.1017/ $\mathrm{S}_{1049096519000428}$

Porter, Nicole Buonocore. 2018. "Ending Harassment by Starting with Retaliation." Stanford Law Review Online 71: 49-61.

Rosenweig, Leah. 2017. "Recap from We the People/Hack for Democracy." MIT Gov/Lab. Available at https://mitgovlab.org/updates/recap-from-we-thepeople-hack-for-democracy.

Stewart, Abigail J., and Virginia Valian. 2018. An Inclusive Academy: Achieving Diversity and Excellence. Cambridge, MA: MIT Press.

Tinkler, Justine E. 2012. "Resisting the Enforcement of Sexual Harassment Law." Law $\mathcal{E}$ Social Inquiry 37 (1): 1-24

Tinkler, Justine E. 2013. "How Do Sexual Harassment Policies Shape Gender Beliefs? An Exploration of the Moderating Effects of Norm Adherence and Gender." Social Science Research 42 (5): 1269-83. 